\title{
Blacks and whites in Cuba have equal prevalence of hypertension: confirmation from a new population survey
}

\author{
Pedro Ordúñez ${ }^{1,2}$, Jay S Kaufman ${ }^{3 *}$, Mikhail Benet ${ }^{2}$, Alain Morejon², Luis C Silva ${ }^{4}$, David A Shoham ${ }^{5}$
} and Richard S Cooper ${ }^{5}$

\begin{abstract}
Background: The excess burden of hypertension among blacks has been a prominent feature of the heath disparities literature, and many scientists presume it to be a stable and inevitable phenomenon. The underlying causes of this disparity can only be disentangled in a setting in which the population does not experience racial stratification of socioeconomic opportunities. While such conditions of racial equality remain uncommon, they may be approximated in Cuba, a country with a persistent policy of social inclusion over the last 5 decades.

Methods: We report on a 2010-2011 stratified probability sample of those aged 15-74 years from the urban population of Cienfuegos in central Cuba. A total of 1496 adults (880 women and 616 men) were recruited and assessed for blood pressure and anthropometrics according to standardized protocols, as well as medication use, educational attainment and observed skin tone (dichotomized into "black" and "white"). Weighted tabular and regression analyses were conducted to estimate adjusted prevalences of hypertension (> 140/90 mmHg) and adjusted prevalence odds ratios for contrasts between the two skin color groups.
\end{abstract}

Results: Mean pressures were higher for men than for women, but overall did not differ importantly between racial groups. About half of all diagnosed hypertensive men were on medication, a proportion that did not vary by racial group. For women, however, adjusted prevalence was somewhat higher among blacks, and treatment and control rates were also somewhat advantaged for white women.

Conclusions: Overall, skin color was unrelated to mean blood pressure or hypertensive status in this population, although among women specifically some racial advantage appears evident in adjusted prevalence and control, and should be investigated further. The overall null result suggests that Cuba may exemplify the social conditions in which racial excess in hypertension, characteristic of much of the western world, is not a necessary reality.

Keywords: Blood pressure, Cuba, Ethnic groups, Hypertension, Stress

\section{Background}

Since the early decades of the $20^{\text {th }}$ century one of the most prominent features of health disparities in the US has been the excess burden of hypertension endured by blacks compared to whites [1]. Despite considerable effort, it has not yet been possible to define the environmental exposures which adequately account for the differential risk, nor have recent efforts in molecular

\footnotetext{
* Correspondence: jay.kaufman@mcgill.ca

${ }^{3}$ Department of Epidemiology, Biostatistics, and Occupational Health, McGill University, 1020 Pine Ave West, Montreal, QC H3A 1A2, Canada

Full list of author information is available at the end of the article
}

epidemiology provided sufficient evidence to support a genetic explanation [2,3]. Environmental factors underlying hypertension are difficult to characterize, and consistently explain a small portion on an individual's risk $[4,5]$. Likewise, genetic studies are still in their infancy, with only $1-2 \%$ of the variance associated with known polymorphisms [6].

One line of argument regarding racial/ethnic differentials in hypertension holds that the cumulative effects of social disadvantage (including nutritional and other behavioral factors, as well as psychosocial stressors resulting from discrimination) would explain the

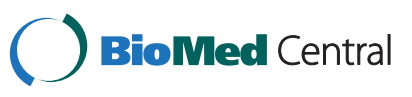


observed excess risk if it could be measured [7]. Epidemiological survey methods are inadequate to capture most of these exposures, however, especially in the psychological domain [8]. In support of this argument, a social class gradient is often observed in hypertension, and clear geographic differences in hypertension burden have been well documented [9].

The "social-structural" theory, which invokes the net effect of discrimination, can only be tested under counterfactual conditions of social equality between blacks and whites. Unfortunately these conditions cannot be found in North America, the UK, or Brazil, where the vast majority of persons in the African Diaspora live. We previously examined racial hypertension differentials in Cuba, a country with a persistently implemented policy of social inclusion stemming from the 1959 revolution, and we found consistent evidence of a diminished prevalence gap between blacks and whites compared to the US $[10,11]$. We report here findings from a new survey in Cuba confirming an absence of substantial racial differentials in blood pressure.

\section{Methods}

The city of Cienfuegos is located in the south and center of the main island of Cuba; with an adult population of 161,828 inhabitants it is the $10^{\text {th }}$ largest in the country [12]. Cienfuegos is the only city in Cuba with population-based data on major cardiovascular risk factors obtained systematically over the last three decades [13]. The Cienfuegos survey was conducted during 2010-2011, based on a probability sample from the urban population aged 15-74 years, and included 1496 adults. The population of Cienfuegos is similar to the general Cuban population in terms of age and race distribution and cardio-vascular mortality (Additional files 1 and 2).

With assistance from the Provincial Department of Statistics and Census, a multi-stage, probability sample was selected from urban Cienfuegos to provide 180-200 persons in gender by 10-year age groups. The sampling design aimed to recruit roughly 2200 adults selected with equal probability within each of the defined agegender groups. For population estimations, the proper weights were computed taking into account the Cienfuegos city resident adult population as most recently estimated in July 2008 [14]. The 2011 survey protocol incorporated portions of a questionnaire developed in a Pan American Health Organization project for risk factor surveillance and intervention for noncommunicable diseases [15].

Data were collected by self-report on a variety of health-related conditions, and anthropometrics were measured directly. Body mass index was calculated as weight in kilograms divided by height in meters squared.
Blood pressure was measured three times at the same sitting using a mercury manometer by trained personnel, and analyses were based on the mean of the last two readings. No terminal digit was assigned more than 25 percent of the values, suggesting an adequate measurement technique. Blood pressure medication use was verified by the physician, who examined the pill bottles. Assignment to the categories of white $(n=1077)$, black $(\mathrm{n}=131)$, and "mulatto" (i.e. mixed race) $(\mathrm{n}=288)$ was made by trained professional interviewers who had participated in the most recent national census. The black and mixed-race categories were combined in the primary analyses, reflecting the standard North American convention of racial dichotomy. Education was dichotomized at "pre-universitario" and above, roughly equivalent to more than high school in the US.

Hypertension was defined as a systolic blood pressure (SBP) of $\geq 140 \mathrm{mmHg}$, a diastolic blood pressure (DBP) of $\geq 90 \mathrm{mmHg}$, or current treatment with antihypertensive agents. "Control in the population" was defined as the percentage of all hypertensives with a SBP of $<140 \mathrm{mmHg}$ and a DBP of $<90 \mathrm{mmHg}$, irrespective of whether they had been previously diagnosed or whether treatment had been recommended. "Control in treated patients" was defined as the number of treated patients achieving the same goal $(<140 / 90 \mathrm{mmHg})$ divided by the number of patients on treatment.

Descriptive analysis was conducted of means and frequencies by gender and skin-color group taking into account the complex sampling design and using EPIDAT, a freely distributed software package developed by the Service of Epidemiology of the Dirección Xeral de Saúde Pública from the "Consellería de Sanidade" (Xunta de Galicia, Spain) and the Health Situation Analysis Program (SHA) of the Pan American Health Organization (http://www.paho.org/english/sha/epidat.htm). Unconditional logistic regression analyses were used to estimate the ratio of prevalence odds (POR) adjusted for multiple covariates. Weighted prevalences were obtained for estimations of the awareness, treatment and control rates at population level.

The study protocol received ethics review and approval from the Comité de Ética de la Investigación Científica (CEIC) of the University of the Medical Sciences of Cienfuegos (UCMC). Participants signed informed consent statements when they enrolled, and again prior to each clinic visit.

\section{Results}

A total of 2193 individuals completed the questionnaire, 1496 of which also participated in the clinical examination (68\%). There was no evidence of differential response by measured characteristics of the participants. A total of 880 women were measured, along with 616 men. 
The combined non-white group (referred to henceforth as "blacks") comprised $27.9 \%$ of the weighted sample, which matches the most recently available census data. Mean pressures were higher for men than for women (Table 1), as were waist circumferences and prevalence of smoking. Women had higher prevalence of selfreported diabetes.

Mean systolic and diastolic blood pressures did not differ importantly between racial groups with both genders combined (Table 2), nor did prevalence of hypertension differ substantially (Table 3 ). Further adjustments for other measured covariates produced no discernible racial excess of hypertension. Stratified by gender, this remained true for men, although in the female stratum blacks had over 4 percentage point higher prevalence of hypertension, which was a significant excess in adjusted models (Table 3 ).

There was no detectable difference in awareness of hypertension by racial group (Table 4), although women showed higher levels of awareness than men overall. About half of all diagnosed hypertensive men were on medication, a proportion that did not vary by racial group. For women, however, the treatment rate was higher than for men, and higher for white women than for black women. Likewise, control in the population did not differ by racial group among men, but was superior in white women compared to black women. Whites showed better control among the treated in both gender strata (Table 4).

\section{Discussion}

The health disadvantage of US blacks in comparison to the majority population extends across the entire spectrum of common conditions and the combined effects of economic and racial discrimination are widely recognized as the over-riding cause [16]. Hypertension is
Table 2 Blood pressure $(\mathrm{mmHg})$ by sex and skin color group, Cienfuegos, 2011

\begin{tabular}{lccccc}
\hline Sex & $\mathbf{N}$ & Whites & $\mathbf{N}$ & Blacks & p-value \\
\hline \multicolumn{5}{c}{ Systolic blood pressure (weighted mean and 95\% Cl) } \\
\hline Men & 456 & $123.3(121.8,124.8)$ & 160 & $122.2(119.7,124.7)$ & 0.46 \\
Women & 621 & $116.7(115.4,117.9)$ & 259 & $117.8(115.4,120.1)$ & 0.42 \\
Total & 1077 & $120.1(119.1,121.1)$ & 419 & $119.8(118.1,121.6)$ & 0.89 \\
\hline \multicolumn{6}{c}{ Diastolic blood pressure (weighted mean and 95\% Cl) } \\
\hline Men & 456 & $81.9(80.7,82.9)$ & 160 & $81.0(78.9,82.9)$ & 0.41 \\
Women & 621 & $76.3(75.4,77.1)$ & 259 & $77.4(75.8,78.9)$ & 0.23 \\
Total & 1077 & $79.1(78.4,79.9)$ & 419 & $79.1(77.8,80.3)$ & 1.00 \\
\hline
\end{tabular}

more commonly seen as a special case, however, and "racial-genetic" explanations have therefore gained much wider acceptance [17]. Racial differences in the primary risk factors, such as obesity, nutrition, alcohol or physical activity, are modest at best and cannot account for the 5-7 mmHg excess systolic blood pressure observed in US adults [18]. While the experience of racial discrimination, through conscious or unconscious mechanisms, has been proposed as the crucial missing risk factor, empirical evidence to support this hypothesis has always been elusive [19]. The Cuban experience, now further replicated in the data presented in this report, offers support to the claim that unmeasured social-structural factors account for higher blood pressures in US blacks, and provide prima facie evidence against the necessity of any vague genetic hypothesis for increased susceptibility.

An unexplained feature of the data presented here is the pattern of gender effects, specifically the excess hypertension risk in black women after covariate adjustment. Although the mean blood pressure differences among women by ethnicity were modest $(1 \mathrm{mmHg}$ for both systolic and diastolic readings), the age-adjusted

Table 1 Descriptive characteristics of the population sample (means, percentages, and 95\% confidence intervals), Cienfuegos, 2011

\begin{tabular}{lccccc}
\hline & \multicolumn{2}{c}{ Whites } & & \multicolumn{2}{c}{ Blacks } \\
\cline { 2 - 3 } & Men $(\mathbf{N}=\mathbf{4 5 6})$ & Women $(\mathbf{N}=\mathbf{6 2 1})$ & & Men (N= 160) & Women (N= 259) \\
\hline Age (years) & $40.9(39.5,42.3)$ & $41.3(40.1,42.5)$ & & $38.0(35.6,40.4)$ & $39.3(37.4,41.2)$ \\
Systolic blood pressure $(\mathrm{mmHg})$ & $123.3(121.8,124.8)$ & $116.7(115.4,118.0)$ & & $122.2(119.7,124.7)$ & $117.8(115.5,120.1)$ \\
Diastolic blood pressure $(\mathrm{mmHg})$ & $81.9(80.7,83.0)$ & $76.3(75.4,77.2)$ & & $81.0(78.9,83.0)$ & $77.4(75.8,79.0)$ \\
Percent hypertensive ${ }^{a}$ & $35.3(31.0,39.8)$ & $26.6(23.6,29.9)$ & & $30.9(24.1,38.7)$ & $31.0(25.8,36.7)$ \\
Body mass index $\left(\mathrm{kg} / \mathrm{m}^{2}\right)$ & $25.7(25.2,26.2)$ & $26.2(25.7,26.7)$ & & $25.7(24.1,27.3)$ & $25.9(25.0,26.9)$ \\
Percent obesity $\left(\mathrm{BMl} \geq 30 \mathrm{~kg} / \mathrm{m}^{2}\right)$ & $15.7(12.4,19.7)$ & $20.1(16.9,23.6)$ & & $14.4(9.5,21.3)$ & $18.0(13.7,23.4)$ \\
Waist circumference $(\mathrm{cm})$ & $89.3(88.1,90.4)$ & $83.7(82.7,84.7)$ & & $86.4(84.3,88.5)$ & $82.1(80.6,83.7)$ \\
Percent current smokers & $25.9(21.8,30.4)$ & $19.4(16.3,23.0)$ & & $30.1(23.0,38.3)$ & $22.5(17.6,28.4)$ \\
Percent with self-reported diabetes & $4.6(3.0,6.9)$ & $8.2(6.3,10.6)$ & & $3.6(1.7,7.5)$ & $6.3(4.1,9.8)$ \\
Percent with post Secondary Education & $71.1(66.5,75.3)$ & $67.4(63.6,71.0)$ & & $70.1(61.9,77.2)$ & $68.1(61.9,73.7)$ \\
\hline
\end{tabular}

${ }^{a} \mathrm{SBP} / \mathrm{DBP} \geq 140 / 90 \mathrm{mmHg}$ or currently taking antihypertensive medication. 
Table 3 Age-adjusted prevalence and 95\% confidence intervals of hypertension in blacks and whites, Cienfuegos 2011

\begin{tabular}{|c|c|c|c|c|c|}
\hline Group & $\mathrm{N}$ & Prevalence $(95 \% \mathrm{Cl})^{1}$ & $\mathrm{POR}^{2}(95 \% \mathrm{Cl})$ & $\mathrm{POR}^{3}(95 \% \mathrm{Cl})$ & $\mathrm{POR}^{4}(95 \% \mathrm{Cl})$ \\
\hline$\overline{T o t a l}$ & 1496 & $31.0(28.8,33.3)$ & & & \\
\hline Men & 616 & $34.1(30.5,37.9)$ & $1.3(1.1,1.6)$ & $1.5(1.1,1.9)$ & $2.1(1.6,3.0)$ \\
\hline Women & 880 & $27.9(25.0,30.6)$ & 1.0 & 1.0 & 1.0 \\
\hline Blacks & 419 & $31.0(26.7,35.7)$ & $1.0(0.8,1.3)$ & $1.2(0.9,1.6)$ & $1.2(0.9,1.6)$ \\
\hline Whites & 1077 & $31.0(28.4,33.8)$ & 1.0 & 1.0 & 1.0 \\
\hline \multicolumn{6}{|l|}{$\overline{M e n}$} \\
\hline Blacks & 160 & $30.9(24.1,38.7)$ & $0.8(0.5,1.2)$ & $0.9(0.6,1.5)$ & $0.9(0.6,1.5)$ \\
\hline Whites & 454 & $35.3(31.0,39.8)$ & 1.0 & 1.0 & 1.0 \\
\hline \multicolumn{6}{|l|}{ Women } \\
\hline Blacks & 259 & $31.0(25.8,36.7)$ & $1.2(0.9,1.7)$ & $1.5(1.1,2.3)$ & $1.7(1.1,2.5)$ \\
\hline Whites & 621 & $26.6(23.6,29.9)$ & 1.0 & 1.0 & 1.0 \\
\hline
\end{tabular}

${ }^{1} \mathrm{SBP} \geq 140 \mathrm{mmHg}$ or DBP $\geq 90 \mathrm{mmHg}$ or currently taking antihypertensive medication.

${ }^{2}$ Crude Prevalence Odds Ratio.

${ }^{3}$ Age-Adjusted Prevalence Odds Ratio.

${ }^{4}$ Prevalence Odds Ratio adjusted for age, education, BMI, waist circumference, alcohol intake, and exercise.

adjusted hypertension prevalence differential was more pronounced (31.0 percent vs. 26.6 percent), and increased with further adjustment. This is a consistent pattern observed in previous surveys as well [11], and along with notable racial differences in control rates by gender suggests that the intersection of race and gender in this society is still a topic that requires deeper understanding [20].

The implications of this finding for Cuba itself are relevant to its overall policy emphasis on primary prevention and public health, as well as health and social equity along numerous dimensions. The pattern observed here contrasts with other Western Hemisphere nations where evidence suggests a more pronounced racial disparity [21-23]. It is therefore tempting to interpret this difference in light of the consciously anti-racist interventions made by the Cuban state over the last 50 years [24]. The challenge for local policy makers, however, will be to maintain these achievements under whatever economic or sociopolitical changes occur, and to encourage greater population surveillance of this type to establish equity benchmarks that can be monitored and defended.

The broader implications for understanding hypertension etiology and the comparison with entrenched racial disparities in the US are less clear. As in all of Latin America, admixture between persons of African and European descent in Cuba has been common since the early days of colonization [25]. Admixture could therefore dilute any putative genetic effect; in the absence of known loci that significantly influence risk of hypertension this question cannot be pursued directly. A plausible role for admixture, however, requires that a relatively small number of loci have a large effect on the trait, and we now have persuasive evidence that genetic predisposition for blood pressure is spread across hundreds of weakly acting polymorphisms [6].

Furthermore, it is crucial to recognize that relative to other world populations, US whites are in fact the exception, not US blacks. Thus, compared to many

Table 4 Age-adjusted prevalences and $95 \%$ confidence intervals of awareness, treatment and control of hypertension in blacks and whites, by sex, Cienfuegos 2011

\begin{tabular}{|c|c|c|c|c|c|c|c|c|}
\hline & \multicolumn{4}{|c|}{ Men } & \multicolumn{4}{|c|}{ Women } \\
\hline & $\begin{array}{l}\text { Whites } \\
(\mathrm{N}=193)\end{array}$ & $\begin{array}{c}\text { Blacks } \\
(\mathrm{N}=62)\end{array}$ & $\begin{array}{l}\text { Difference } \\
(95 \% \mathrm{Cl})\end{array}$ & $p$ & $\begin{array}{l}\text { Whites } \\
(\mathrm{N}=224)\end{array}$ & $\begin{array}{c}\text { Blacks } \\
(\mathrm{N}=107)\end{array}$ & $\begin{array}{l}\text { Difference } \\
(95 \% \mathrm{Cl})\end{array}$ & $\bar{p}$ \\
\hline $\begin{array}{l}\text { Aware of being hypertensive: } \\
\qquad \%(95 \% \mathrm{Cl})\end{array}$ & $54.7(46.9,62.3)$ & $55.3(41.2,68.6)$ & $0.6(0.4,0.8)$ & 0.99 & $78.0(71.3,83.5)$ & $71.8(61.0,80.6)$ & $6.2(6.1,6.3)$ & 0.16 \\
\hline $\begin{array}{l}\text { Currently taking medication: } \\
\qquad \%(95 \% \mathrm{Cl})\end{array}$ & $42.9(35.5,50.6)$ & $47.7(34.3,61.5)$ & $4.8(4.6,5.0)$ & 0.85 & $71.4(64.3,77.6)$ & $60.6(49.9,70.4)$ & $10.8(10.7,10.9)$ & 0.05 \\
\hline $\begin{array}{c}\text { Control in the population': } \\
\qquad \%(95 \% \mathrm{Cl})\end{array}$ & $21.4(15.8,28.4)$ & $17.0(9.2,29.3)$ & $4.4(4.1,4.7)$ & 0.55 & $37.8(31.2,44.9)$ & $24.6(17.0,34.1)$ & $13.2(13.0,13.4)$ & 0.01 \\
\hline $\begin{array}{l}\text { Control among the treated }{ }^{2} \text { : } \\
\qquad \%(95 \% \mathrm{Cl})\end{array}$ & $50.0(38.6,61.4)$ & $35.7(20.0,55.1)$ & $14.3(14.1,14.5)$ & 0.04 & $53.0(44.8,61.0)$ & $40.5(28.9,53.3)$ & $12.5(12.3,12.7)$ & 0.03 \\
\hline
\end{tabular}

\footnotetext{
${ }_{1}^{1}$ Percent of all hypertensives with measured blood pressure $<140 / 90 \mathrm{mmHg}$.

2 Percent of treated hypertensives with measured blood pressure $<140 / 90 \mathrm{mmHg}$.
} 
European countries, particularly Eastern Europe, Russia and Finland, blood pressure levels in US blacks are the same or substantially lower [26]. A standardized international comparative study also demonstrated that blood pressures in the English-speaking Caribbean are similar to those found among US whites [27]. The salience of these international comparisons is reinforced by data on mortality rates from stroke [28]; US whites have among the lowest death rates from stroke in the world, while 10-fold higher rates are found in Russia [29]. The perception of unusual hypertension risk among US blacks is therefore in part the result of a myopic interpretation of a comparison restricted to US whites.

\section{Conclusion}

The data presented here of course have important limitations. The sample size in this study is relatively small, and restricted to a single urban center. Racial group was assigned based on observations by interviewers and, particularly in the Spanish Caribbean, is a categorization scheme with ambiguous borders. Nonetheless, in the context of a growing appreciation for the unique social environment created in Cuba for the study of racial disparities [30], this study confirms that the commonly observed black excess in blood pressure is neither a fixed nor a natural phenomenon, and suggests that the study of this particular sociopolitical environment may offer a unique lens into the etiology of the racial disadvantage that plagues the developed world.

\section{Additional files}

\section{Additional file 1: Age-adjusted heart disease mortality rate per 100,000 inhabitants in Cuba and its provinces, 2011. \\ Additional file 2: Population pyramid from Cienfuegos and Cuba, 2002.}

\section{Abbreviations}

mmHg: Millimeters of mercury; US: United States; SBP: Systolic blood pressure; DBP: Diastolic blood pressure; POR: Prevalence odds ratio.

\section{Competing interests}

The authors declare no financial conflict of interests. Although the conduct of the survey was supported by the Ministry of Public Health of Cuba, authors received no additional financial payments for the analyses reported here, and the Ministry had no role in the analysis or interpretation of the data. JSK reports support from the Canadian Research Chairs Program, which also defrayed the publication charges for the article but which had no influence on the conduct of the study or on the content of the paper.

\section{Authors' contributions}

PO, JSK, DAS and RSC drafted the manuscript. PO, MB, AM and LCS designed the study and oversaw the collection of the data. JSK and LCS provided statistical analysis and support. All authors provided critical comments on the manuscript, participated in revisions of the text, and approved the final version of the manuscript.

\section{Author details}

${ }^{1}$ Project for Chronic Disease Prevention and Control, Pan American Health Organization, Washington DC 20037, USA. ${ }^{2}$ Centro de Estudios sobre
Enfermedades Crónicas, Universidad de Ciencias Médicas, Cienfuegos 55100, Cuba. ${ }^{3}$ Department of Epidemiology, Biostatistics, and Occupational Health, McGill University, 1020 Pine Ave West, Montreal, QC H3A 1A2, Canada. ${ }^{4}$ Centro Nacional de Información de Ciencias Médicas, La Habana, Cuba. ${ }^{5}$ Department of Preventive Medicine and Epidemiology, Loyola University Stritch School of Medicine, Maywood, IL 60153, USA.

Received: 2 May 2012 Accepted: 21 February 2013

Published: 24 February 2013

\section{References}

1. Cooper RS, Kaufman JS: Race and hypertension: science or nescience? Hypertension 1998, 32:813-816.

2. Cooper RS, Rotimi CN, Ward R: The puzzle of hypertension in African Americans. Sci American 1999, 280(2):56-63.

3. Cooper RS, Zhu X: Racial differences and the genetics of hypertension. Curr Hypertens Rep 2001, 3:19-24.

4. Kaufman JS, Cooper RS, McGee DL: Socioeconomic status and health in blacks and whites: the problem of residual confounding and the resiliency of race. Epidemiology 1997, 8(6):621-628.

5. Cooper RS: Genetic factors in ethnic disparities in health. Critical Perspectives on Racial and Ethnic Disparities in Late Life. Washington, DC: National Academy of Sciences/National Research Council Press; 2004:267-309.

6. International Consortium for Blood Pressure Genome-Wide Association Studies: Genetic variants in novel pathways influence blood pressure and cardiovascular disease risk. Nature 2011, 478(7367):103-109.

7. Tomson J, Lip GY: Blood pressure demographics: nature or nurture. . .genes or environment? BMC Med 2005, 3:3.

8. Laveist T, Pollack K, Thorpe R Jr, Fesahazion R, Gaskin D: Place, not race: disparities dissipate in southwest Baltimore when blacks and whites live under similar conditions. Health Aff (Millwood). 2011, 30(10):1880-1887.

9. Grotto I, Huerta M, Sharabi Y: Hypertension and socioeconomic status. Curr Opin Cardiol 2008, 23(4):335-339.

10. Ordúñez-García PO, Espinosa-Brito AD, Cooper RS, Kaufman JS, Nieto FJ: Hypertension in Cuba: evidence of a narrow black-white difference. $J$ Hum Hypertens 1998, 12(2):111-116.

11. Ordunez P, Munoz JLB, Espinoza-Brito A, Silva LC, Cooper RS: Ethnicity, education and blood pressure in Cuba. Am J Epidemiol 2005, 162:49-56.

12. Cuba: Oficina Nacional de Estadísticas. Censo de Población y Viviendas. Cuba: Informe Naciona; 2002. http://www.cubagob.cu/otras_info/censo/ tablas_html/i_6.htm.

13. Cooper RS, Orduñez P, Iraola MD, Munoz JL, Espinosa-Brito A: Cardiovascular disease and associated risk factors in Cuba: prospects for prevention and control. Am J Public Health 2006, 96(1):94-101.

14. Silva LC, Benet M, Morejón A, Ordúñez PO: An efficient sampling approach to surveillance of non-communicable disease risk factors in Cienfuegos, Cuba. MEDICC Rev 2012, 14(4):36-39.

15. Pan American Health Organization: Pan American version of the WHO STEPwise approach to chronic disease risk factor surveillance- v2.1. Available at: http://new.paho.org/hq/dmdocuments/2009/STEPSquestionnaire.pdf. Accessed: April 26, 2012.

16. Williams DR, Sternthal M: Understanding racial-ethnic disparities in health: sociological contributions. J Health Soc Behav 2010, 51(Suppl):S15-S27.

17. Kaufman JS, Hall SA: The slavery hypertension hypothesis: dissemination and appeal of a modern race theory. Epidemiology 2003, 14(1):111-118.

18. Wright JD, Hughes JP, Ostchega Y, Yoon SS, Nwankwo T: Mean systolic and diastolic blood pressure in adults aged 18 and over in the United States, 2001-2008. Natl Health Stat Report. 2011, 35:1-24.

19. Williams DR, John DA, Oyserman D, Sonnega J, Mohammed SA, Jackson JS: Research on discrimination and health: an exploratory study of unresolved conceptual and measurement issues. Am J Public Health 2012, 102(5):975-978.

20. González Pagés J: En busca de un espacio: historia de mujeres en Cuba. La Habana: Ediciones de Ciencias Sociales; 2003.

21. Ryder E, Silva E, Sulbarán T, Fernández V, Campos G, Calmon G, Clavell E, Raleigh $\mathrm{X}$, Florez $\mathrm{H}$ : Black Hispanics have a worse cardiovascular risk profile than mixed Hispanics in Venezuela. Invest Clin 2007, 48(1):45-55.

22. Sichieri R, Oliveira MC, Pereira RA: High prevalence of hypertension among Black and Mulatto women in a Brazilian survey. Ethn Dis 2001, 11(3):412-418. 
23. Borrell LN: Self-reported hypertension and race among Hispanics in the National Health Interview Survey. Ethn Dis 2006, 16(1):71-77.

24. Adams HC: Race and the formation of Cuban national and cultural identity. In Global Multiculturalism: Comparative Perspectives on Ethnicity, Race, and Nation. New York: Rowman and Littlefield Publishers; 2001:193-210.

25. Mendizabal I, Sandoval K, Berniell-Lee G, Calafell F, Salas A, Martínez-Fuentes A, Comas D: Genetic origin, admixture, and asymmetry in maternal and paternal human lineages in Cuba. BMC Evol Biol 2008, 8:213.

26. Cooper RS, Wolf-Maier K, Luke A, Adeyemo A, Banegas JR, Forrester T, Giampaoli S, Joffres M, Kastarinen M, Primatesta P, Stegmayr B, Thamm M: An international comparative study of blood pressure in populations of European vs. African descent. BMC Med. 2005, 3:2.

27. Cooper R, Rotimi C, Ataman S, McGee D, Osotimehin B, Kadiri S, Muna W, Kingue S, Fraser H, Forrester T, Bennett F, Wilks R: Hypertension prevalence in seven populations of African origin. Am J Public Health 1997, 87:160-168

28. Wolf Maier K, Cooper RS, Banegas JR, Biampaoli S, Hense H, Joffres M, Kastarinen M, Poulter N, Primatesta P, Rodriguez-Artalejo F, Stegmayr B, Thamm M, Tuomilehto J, Vanuzzo D, Vescio F: Hypertension and blood pressure level in six European countries, Canada and the US. JAMA 2003, 289:2363-2369.

29. Redon J, Olsen M, Cooper RS, Zurriaga O, Martinez M, Laurent F, Chiftkova R, Coca A, Mancia G: Variation in stroke mortality and secular trends in 39 countries from Europe and Central Asia: implications for blood pressure control. Eur Heart J 2011, 32:1424-1431.

30. Cooper RS, Kennelly JF, Orduñez-Garcia P: Health in Cuba. Int J Epidemiol 2006 Aug, 35(4):817-824

doi:10.1186/1471-2458-13-169

Cite this article as: Ordúnez et al:: Blacks and whites in the Cuba have equal prevalence of hypertension: confirmation from a new population survey. BMC Public Health 2013 13:169.

\section{Submit your next manuscript to BioMed Central and take full advantage of:}

- Convenient online submission

- Thorough peer review

- No space constraints or color figure charges

- Immediate publication on acceptance

- Inclusion in PubMed, CAS, Scopus and Google Scholar

- Research which is freely available for redistribution 